\title{
Business Intelligence Adoption in Developing Economies: A Case Study of Ghana
}

\author{
Quist-Aphetsi Kester ${ }^{1,2}$, Mansah Preko 1, 2, 3 \\ ${ }^{1}$ Graduate School, Ghana Technology University College, Ghana \\ ${ }^{2}$ Coventry Graduate School, Coventry University, United Kingdom \\ ${ }^{3}$ Ghana Institute of Management and Public Administration Ghana
}

\begin{abstract}
In this era of competitive market and ever sharply changing market trends, there is a need for timely and integrated engagement of information systems for effective decision making. Developed countries and developed economies are evolving their information systems by aligning them to incorporate adaptive approaches to business models in realtime with forecasting capabilities. This has seen changes leading to the adoption of service-based system integration to big data platforms. Developing economies and developing countries, to some extent, incorporate business intelligence techniques in evaluating their data to make informed decisions. In our work, we considered the banking sector in developing economies with focus on Ghana as a case study in assessing the impact of the adoption of business intelligence tools with respect to its usefulness in the competitive emerging financial market. At the end of our study, those who adapted the approaches in business intelligence have experienced effective competitive advantage and dominance in the market and have excelled in their product delivery to customer satisfaction.
\end{abstract}

\section{General Terms}

Information Systems, Business Intelligence, Information Technology Management, Market Intelligence

\section{Keywords}

Business Intelligence, banking, information system, Information technology

\section{INTRODUCTION}

There has been widespread adoption of various technologies in the banking industry of Ghana in order to remain competitive. However, the proliferation of technology and its rapidly changing trends are forcing industry players to move along with the emerging technologies. The banking industry is one of the industries which has been recognized globally to have real need for information and knowledge. Hence, moving along technological lines in order to be efficient and effective in business cannot be emphasised. Yet, it is perceived that people in developing countries are slow to adapt to new technologies. The study therefore seeks to identify factors that influence the adoption of technology.

Secondly, several banks in the Ghanaian banking industry are perceived to use technologies that employ the use of Business Intelligence in their operations due to the nature of the banking job. However, it is not known to what extent users of these systems know about Business Intelligence and the extent to which it could be useful to their individual organisations. By this extension, the research seeks to ascertain how well the banking industry in Ghana know about Business Intelligence, how well it has been adapted and how useful it has been to them as an industry.

With the introduction of IT, a lot of businesses and industries which deal with large volumes of data are forced to gather electronic data from different sources, understand, and harness the data to make meaningful decisions. This has encouraged a number of them to adapt to computer based intelligence in their operations to enhance efficiency and promote quick decision making. For now, the banking industry has been identified as one of such industries which has proven to have a real need for the data they collect. For example, the industry is known to collect huge volumes of data from hundreds and thousands of customers on a daily basis to help them develop customised products and services to suit each category of customers. Besides, it is also one of the industries that is known to be using their data for performing several analysis and forecasting in order to stay competitive. Meanwhile, all these processes require the application ICTs to provide the platform for such analyses to be performed; this is where the applications of Business Intelligence (BI) comes into play.The concept of Business Intelligence in relation to the banking industry can be very broad. In order to describe the focus of the research, we considered the major operational banks in Ghana. The research targeted the head offices of the various banks in order to have accurate information and also to help make generalisation for the branches. Next, the research evaluated how BI has been adapted in the Ghanaian banking industry by measuring certain variables, i.e. awareness, usefulness, and ease of use against adoption. This would subsequently give the basis to determine the impact of the adoption of BI systems and technologies in the banking industry in Ghana.

\section{LITERATURE REVIEW}

In recent years, there has been a lot of literature on Business Intelligence and its application in industry. Although there has not been a generally settled commencement of BI, various authors have promoted their own ideas of its connotations. For example, Hannula and Pirttimaaki conducted an empirical study of Business Intelligence on the top Finnish companies [1]. The objective of this study was to find out how common Business Intelligence activities were, and how it was applied in large Finnish companies. In another study, Pejic Bach et. al researched into the Influence of BI implementation to the Bank's performance, a case of the Croatian Banking industry [2]. Tabatabaei also evaluated the Business Intelligence Maturity Level in Iranian Banking industry. All these studies have contributed to literature and knowledge in the applications of Business Intelligence in the banking industry 
[3]. Business Intelligence has been defined and explained in many ways by several authors which in many cases, depend on the context in which it is being represented. For example, Turban et al defines Business Intelligence as an umbrella, which includes architectures, tools, databases, applications, and methodologies with an objective of enabling interactive access to data, enabling exploitation to the data and providing managers and analysts' access to use it. They explained BI as the new approach in which companies collect, organize and apply information. In their view, the old ways of doing things have changed to reflect new technologies since companies need to make real time decisions based on their data [4]. Hill and Scott suggest that, effective business decisions depend on the acquisition, processing and utilization of applicable knowledge which they believed that some information or knowledge is basically more valuable and more sensitive than others. Hence, they viewed the concept of BI as a complex one, and really exploded the often-held view that it is some kind of update of a modern business database. They further argued that the existence of different and disparate data sources in most industries which implement Business Intelligence has raised the concept of cleaning their data and linking the different sources, and also making access to them in a meaningful approach. Their argument was to lay emphasis on the fact that Business Intelligence makes use of existing meaningful data of an organisation. Hence, the implementation of BI systems in an organisation does not automatically guarantee reliable information for decision making and support [5]. Herschel and Jones looked at BI as a set of technologies that gather and analyse data to improve decision making [6]. In contrast, Tabatabaei saw BI as a process rather than a technology; according to him, the process of BI consists of major three steps, i.e. data gathering, data analysis and actions taken based on the data. Hence the process of Business Intelligence depends on these three steps [3]. Meanwhile, Reinschmidt also considered Business Intelligence as an easier and a more quickly decision making process, and not a business process. In his view, there are huge amounts of data that are collected in every business on a daily basis from different sources. As a result, there must be a better way of combining and organising these huge amounts of data in order to make informed business decisions. This is because; intelligence is all about making decisions that can direct an organisation to obtain competitive advantage and learning to control those advantages [7].By gaining competitive advantage in the global business environment, challenges such as market globalisation, augmented bargaining power of suppliers, demanding and informed customers, strategic competitors and emerging technologies are inevitable. With these challenges in the background, businesses need to deploy other systems that will enable them to keep up with industry players in order to stay in competition. It is in this context that Chau et al, described Business Intelligence as competitive intelligence, commercial intelligence or corporate intelligence. According to them, these terms are used to express the process of monitoring a firm's external environment to gain relevant information to aid in its decision making process. In today's competitive marketplace, most people consider Business Intelligence as a competitive advantage. This is because the knowledge and information about customers, suppliers, products, partners, etc. help in making strategic decisions which could consequently lead to revenue increment and profit augmentation in an organisation [8].
In this study, Business Intelligence is considered as a set of tools and technologies that aid businesses and organisations to make strategic business decisions based on available data. This has been established from the understanding that, Business Intelligence in itself cannot be considered as part of an organisation's business processes, rather it is considered as a tool or technology that aids those business processes.

Besides the conventional reporting tools such as spreadsheets, data mining and warehousing tools, Online Analytical Processing (OLAP), digital dashboards, etc. there are other BI reporting tools that provide visual interfaces for admittance and navigation through multidimensional data sources that are stored in transactional systems. This indicates that decision makers and analysts will have quicker and easier access to update information repeatedly, which supports quicker and better decision-making. For example, an impressive BI tool can generate different views from available data system in an organisation. In this case, a scaled data warehouse can provide a rich, timely, well-structured and rinsed information to a BI tool to support organisational decision making. It only needs a few seconds to use a BI software to generate requested views of an organisation or an enterprise [8].

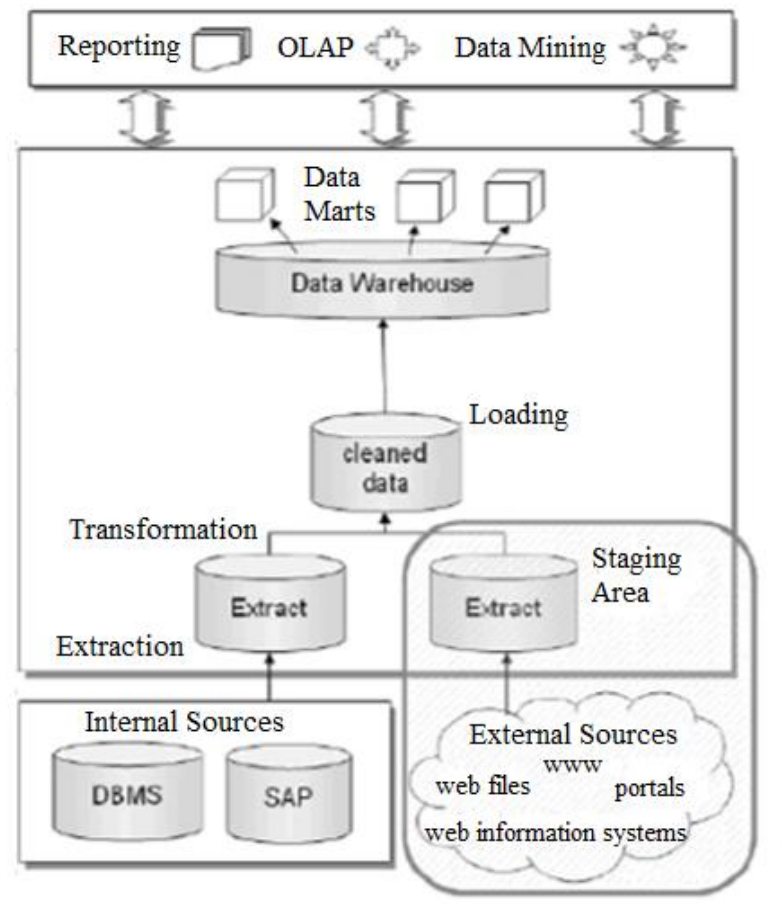

Fig 1: Business Intelligence Tools

In a research conducted by Chou et al. indicated that BI tools play a very critical role in enhancing the quality of decision making. According to them, businesses need to centre their activities on Business Intelligence in the areas of profitability analysis, cost reduction, target marketing, product or service usage analysis, relationship marketing, and Customer Relationship Management (CRM) in order to make their businesses more competitive. Some businesses employ specialized Business Intelligence tools to support their activities. For instance, cube analysis BI tools are usually used to supply straightforward slice-and-dice analytical capabilities to managers, whereas Enterprise Reporting tools are used by report writers to generate highly formatted static reports that are predetermined for broad division to many people. The relational Online Analytical Processing (OLAP) tools are also used to permit power users to query databases for any answers in the database and is able to surf down to the lowest level of 
transactional information. Several other BI tools are available for their distinct purposes [8].Turban et al. also indicated that the process of Business Intelligence is based on transformation of data to information, then to decisions and ultimately into actions [9].The actual Business Intelligence process consists of a series of activities which involve identification, gathering, development, analysis, and information dissemination. One of the significant steps in the identification process is to identify customers, stakeholders, suppliers, labour unions, competitors, governments and political parties, public interest groups, etc. or other variables in the environment to be monitored [8].

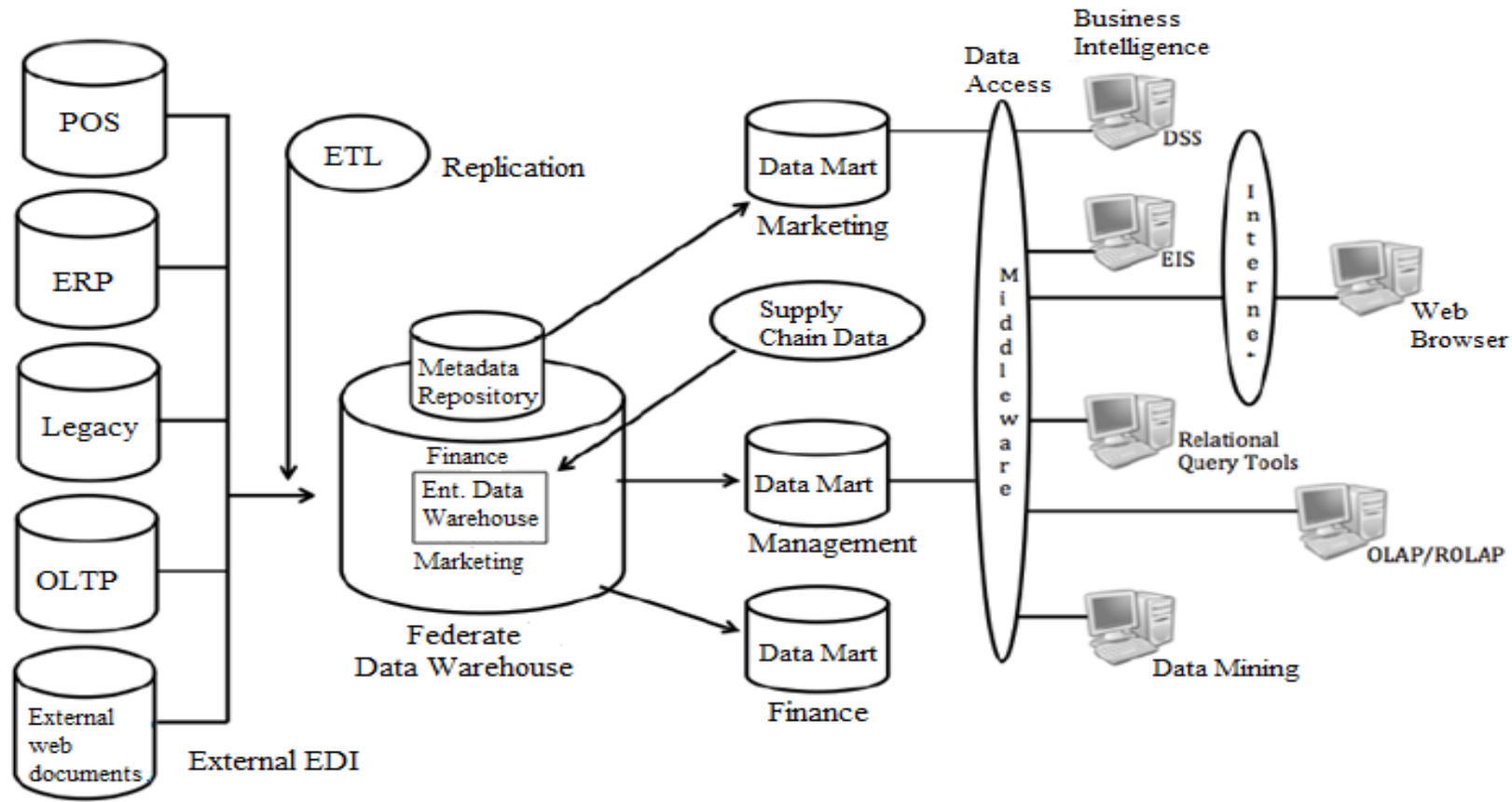

Fig 2: BI Processes. Source: Karlsen \& Eidene, 2012

Azvine et al introduced the different views or processes of Business Intelligence and has considered BI to be all about how to capture, access, understand, analyse and turn one of the most valuable resources of an organisation, i.e. data, into workable information in order to improve business performance. Other researchers have also explained the BI process as a way of gathering meaningful information about the subject matter that is being researched into, in order to help those individuals analysing the information to draw conclusions or make realistic assumptions. Figure 2 below depicts how BI processes are being executed in industry and organisations [10].

A typical BI process usually begins with the collection of data from the different departments of an organisation and later transforming it into a standard format. The data is then loaded into a data warehouse which undergoes the Extraction, Transformation and Loading (ETL) processes. After these processes, when the data has been cleaned and stored, it is then transformed into static data which can be used for analytical and operational purposes. With the aid of BI systems, organisations can collect and use the specific data to create reports, projections, analysis, etc.

It is in this context that Michalewicz et al. described the common objectives of Business Intelligence systems in three major steps, i.e.

i. Admitting data from a number of different sources;

ii. Converting the data into information, and subsequently into knowledge; and

iii. Providing a usable graphical interface to display the knowledge.

From their perspective, a BI system is responsible for collecting and processing data, and then presenting knowledge in a friendly way, which in the end, enhances the end user's ability to make meaningful decisions. With this understanding, they proposed a model (i.e. Figure 3 below) that demonstrates the processes that support a traditional business intelligence system.

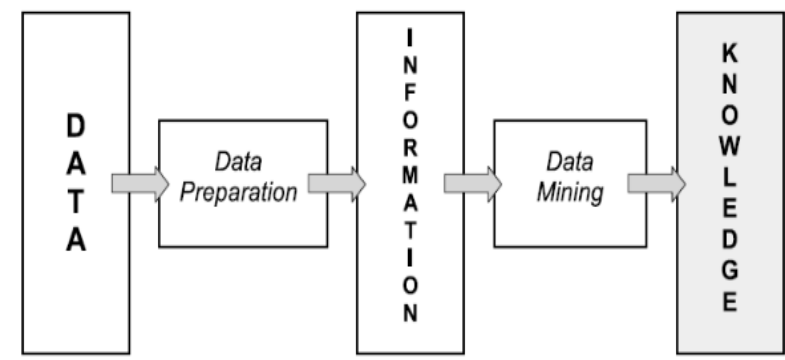

Fig 3: Transforming Data into Knowledge using BI.

\section{METHODOLOGY}

This research adapts the Technology Acceptance Model (TAM) by Davis to examine the factors that influence the adoption and impact of Business Intelligence on the banking industry in Ghana. According to Baraghani, a diffusion of innovative technology is highly related to communication channels, individuals, organisational members, and social system except for technology itself. Since the research focuses on BI in the banking industry, which is considered as an innovative technology in Ghana, organisational and social systems such as peer and superior influence, self-efficacy in computing or related IT systems, and external source constraints would play significant roles in determining the acceptance/adoption of BI in the Ghanaian banking industry [4]. 
The Technology Acceptance Model (TAM) by Davis is possibly one of the most frequently used models in conducting IT research. This theoretical model is based on the Theory of Reasoned Action (TRA) which is a general model concerned with individuals' intended behaviours. According to the Theory of Reasoned Action, an individual's performance is determined by the individual's attitude and subjective norms concerning the behaviour in question [12]. Technology Acceptance Model determines the user acceptance of any technology's perceived usefulness (PU) and perceived ease of use (PEOU). The theory suggests that user perceptions of usefulness and ease of use determine attitudes towards using a system, and behavioural intentions to use a system determines the system's actual use, which is consistent with the Theory of Reasoned Action.

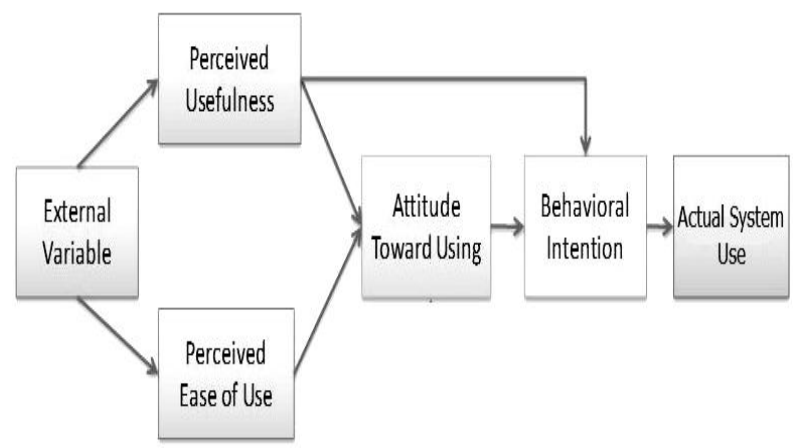

Fig 4: Technology Acceptance Model, TAM by Davis

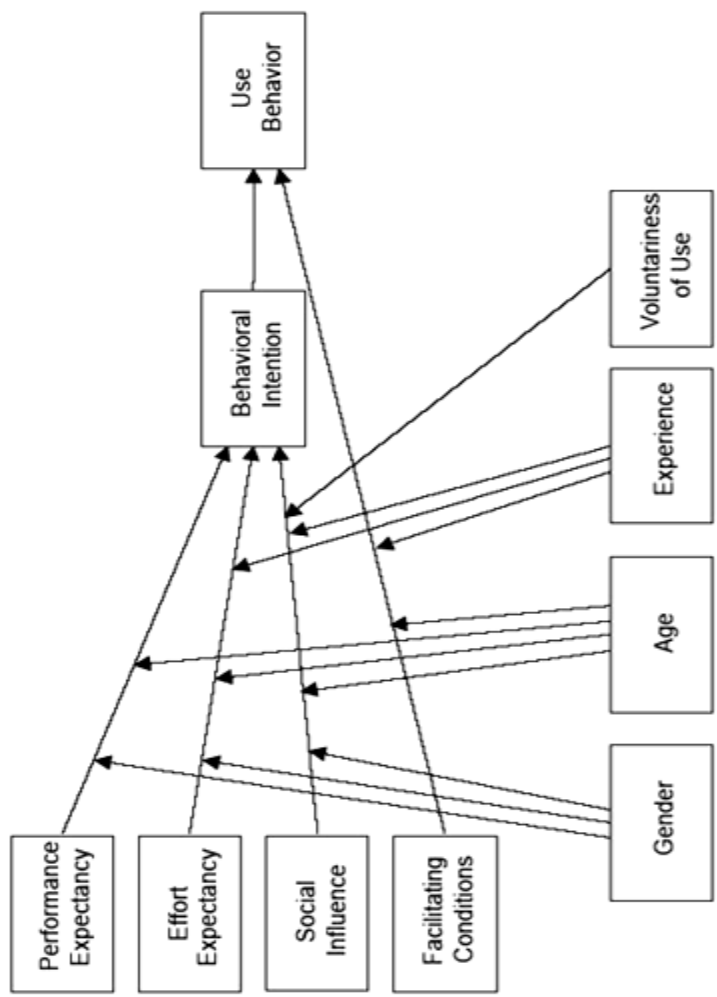

Fig 4: User Acceptance of Information Technology [13]

The entire process for this study is formulated in the conceptual design below, i.e. the Research Project Lifecycle. The project was designed in five main phases with the most important deliverables of each phase, summarized in the boxes below each phase.

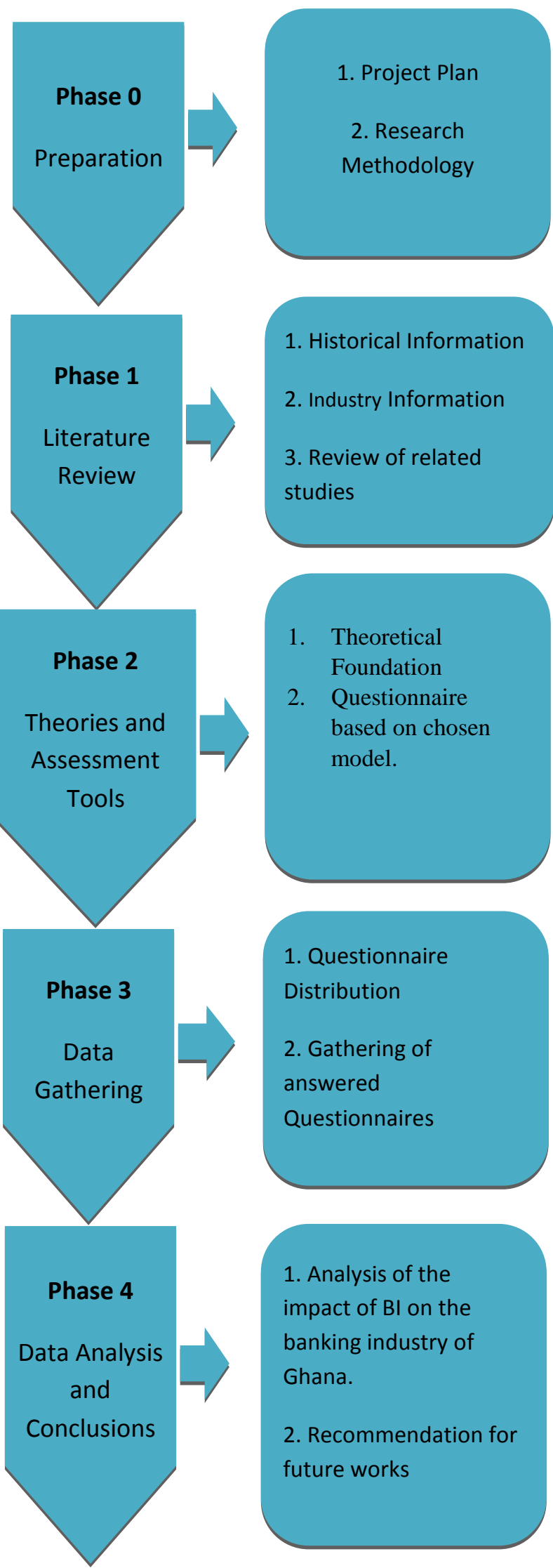

Fig 5: A summary of the entire research process 


\section{RESULTS AND ANALYSIS}

While Business Intelligence is considered as a technology in this study, its initial adoption in essence, could strongly depend on both awareness of the technology and peoples' perception about using it (i.e. behavioural intensions to use the technology). Hence a modification of the Technology Acceptance Model (TAM) was seen to be a more comprehensive model to understand the acceptance behaviour and adoption of BI tools and technologies in the Ghanaian banking industry. The research model for this study is shown in the diagram below:

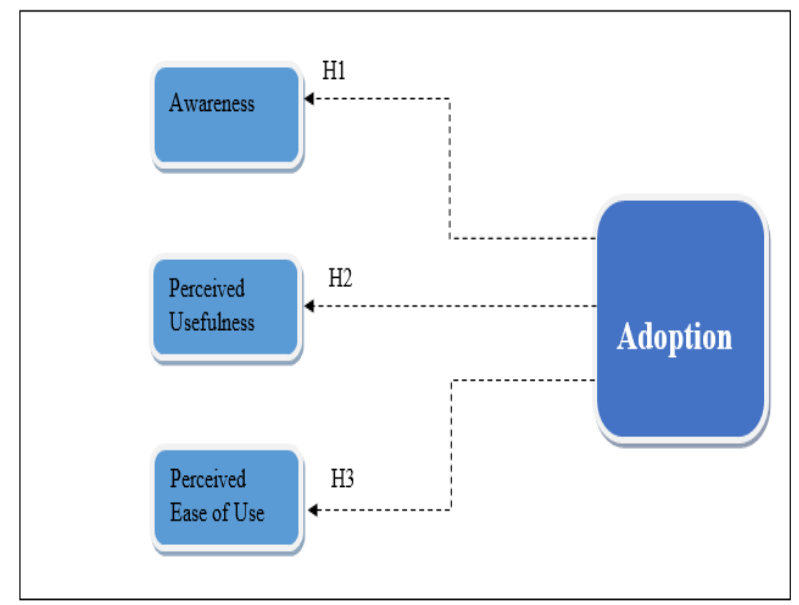

Fig 6: Research Model

While the first hypothesis (H1) indicates a direct prediction of the awareness of a technology to its adoption, $\mathrm{H} 2$ and $\mathrm{H} 3$ present an indication of users' behavioural intension towards the adoption of a technology after it is perceived to be useful and easy to use. The hypothesis was tested and verified using empirical data.

Since the researcher had no control over the actual behavioural proceedings of the various banks, a survey was found to be most appropriate for the study by way of random sampling. Sampling process was chosen in order to make the results generalizable for the entire banking population in Ghana. The following results were obtained from the data gathered:

Table 1: Gender Profile of Respondents

\begin{tabular}{|l|l|}
\hline Gender & Percentage (\%) \\
\hline Male & $97.3 \%$ \\
\hline Female & $2.7 \%$ \\
\hline Total & $100 \%$ \\
\hline
\end{tabular}

Table 1 above shows the number of male and female respondents of the questionnaires. Out of the respondents we had males representing (97.3\%), and female respondent representing $(2.7 \%)$ of the totals. The males represented the vast majority of respondents as compared to females. This indicated that a lot of females are not engaged in core IT activities in the Ghanaian banking industry, and males are more likely to adapt to a new technology quickly in the banking industry than females. The diagram shows the gender profile of the respondents.
Table 2: Age Profile of Respondents

\begin{tabular}{|l|l|}
\hline Respondents' Age (Years) & Percentage (\%) \\
\hline $20-30$ & 78.4 \\
\hline $31-40$ & 18.9 \\
\hline $41-50$ & 2.7 \\
\hline Above 50 & 0 \\
\hline
\end{tabular}

The table above gives the age distribution of the respondents. From the analysis above, it was realized that most users of BI tools in the banking industry were between the ages of $20-30$ years which represents $78.4 \%$ of the total sample population. This indicates that, people in this age group are more technology inclined and are likely to accept and adapt new technologies as and when they come. However, people in the ages of $40-50$ and those above fifty were not more equipped with using BI systems and technologies. This means that, people in this age group are not likely to get use easily to new technologies.

Table 3: Respondents' Educational Profile

\begin{tabular}{|l|l|}
\hline Respondents' Education & Percentage (\%) \\
\hline $\begin{array}{l}\text { Certificate (Professional, diploma, } \\
\text { etc.) }\end{array}$ & 2.7 \\
\hline Undergraduate & 0 \\
\hline Graduate & 73 \\
\hline Postgraduate & 24.3 \\
\hline
\end{tabular}

The table above gives the distribution of the educational profile of the respondents. From the analysis, it was observed that majority of the users of IT systems including BI technologies in the banking industry were graduates or had had a postgraduate study. Again, the responses from these individuals showed that most of them learnt about Business Intelligence and its benefits before entering into the banking sector although a few of them learnt about the use of these systems on the job. This indicates that, the level of education and age are also factors that can contribute 'to the awareness of a new technology.

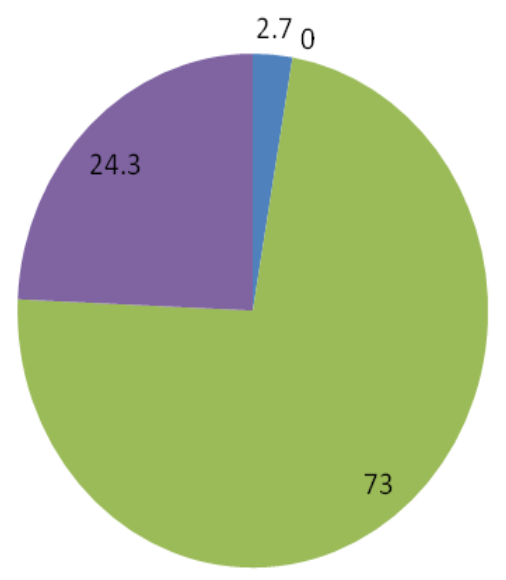

n Certificate (Professional, diploma, etc.)

- Undergraduate

n Graduate

- Postgraduate

Figure 7: Respondent's Educational Level 
Table 4: Popular BI systems and technologies being used by respondents

\begin{tabular}{|l|l|}
\hline BI Tools \& Technologies & Percentage (\%) \\
\hline $\begin{array}{l}\text { Business Objects. (Popularly known as } \\
\text { "BO") }\end{array}$ & $37.9 \%$ \\
\hline $\begin{array}{l}\text { Oracle Business Intelligence (Also } \\
\text { Known as Oracle BI) }\end{array}$ & $16.2 \%$ \\
\hline QlikView BI and Reporting tool & $5.4 \%$ \\
\hline SQL Server Reporting Services & $2.7 \%$ \\
\hline Moody's Risk Analyst & $2.7 \%$ \\
\hline $\begin{array}{l}\text { Other Management Information System } \\
\text { (MIS) }\end{array}$ & $2.7 \%$ \\
\hline BO and Oracle BI & $18.9 \%$ \\
\hline & $13.5 \%$ \\
\hline None & \\
\hline
\end{tabular}

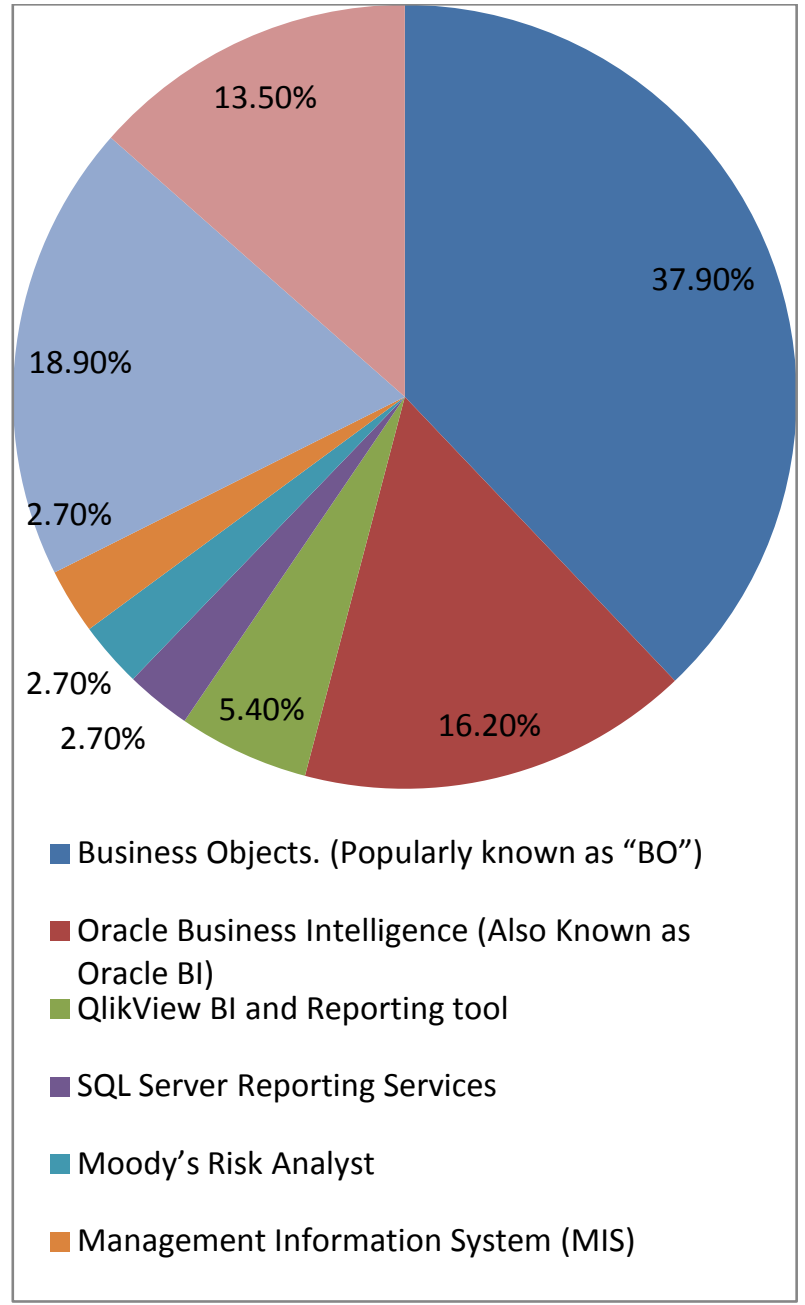

Figure 7: Popular BI systems and technologies being used by respondents
Table 5: Organisational Level Profile of Respondents

\begin{tabular}{|l|l|}
\hline Organisational Level & Percentage (\%) \\
\hline Strategic Level & 5.4 \\
\hline Business Level & 62.2 \\
\hline Others & 32.4 \\
\hline
\end{tabular}

The table above gives a distribution of the organisational level representations of banking staff who were involved in the use of BI systems and technologies.

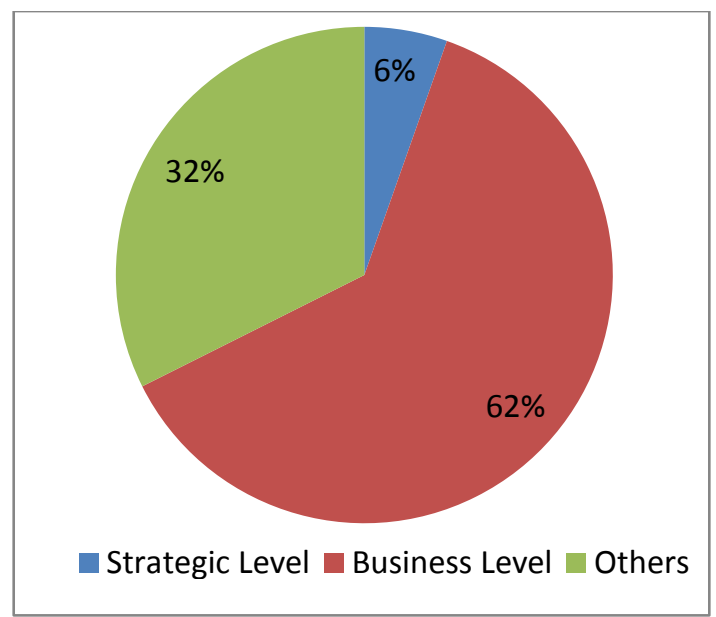

Figure 8: Organisational Level Profile of Respondents

From the data gathered and analysis made, it was observed that $62.2 \%$ were represented at the business level in the banking industry. This implied that the highest number of BI systems and technology users were not at the represented at the strategic level where major decisions are made. Only 5.4\% were represented at the strategic level. However $32.4 \%$ were others.

Table 6: Usefulness of BI tools and technologies banking activities * Continuous adoption of BI technologies.

\begin{tabular}{|c|c|c|c|c|c|c|}
\hline $\begin{array}{l}c \\
0 \\
0 \\
\mathbb{8}\end{array}$ & & $\begin{array}{l}\text { Cont } \\
\text { of BI }\end{array}$ & $\begin{array}{l}\text { uous ad } \\
\text { echnolo }\end{array}$ & $\begin{array}{l}\text { ption } \\
\text { ies }\end{array}$ & & \\
\hline $\begin{array}{l}\infty \\
\infty \\
0 \\
\infty \\
\varpi \\
0\end{array}$ & & 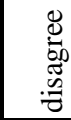 & 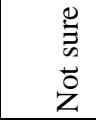 & 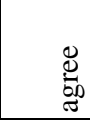 & 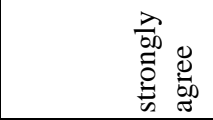 & Total \\
\hline 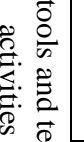 & 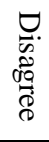 & $.0 \%$ & $.0 \%$ & $2.7 \%$ & $5.4 \%$ & $8.1 \%$ \\
\hline 它 & $\underset{\stackrel{Z}{Z}}{\mathrm{Z}}$ & $.0 \%$ & $2.7 \%$ & $2.7 \%$ & $.0 \%$ & $5.4 \%$ \\
\hline 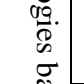 & $\begin{array}{l}\vec{D} \\
\overrightarrow{\sigma o g} \\
\overrightarrow{0}\end{array}$ & $5.4 \%$ & $5.4 \%$ & $8.1 \%$ & $16.2 \%$ & $35.1 \%$ \\
\hline 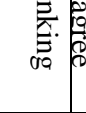 & 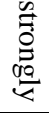 & $2.7 \%$ & $8.1 \%$ & $16.2 \%$ & $24.3 \%$ & $51.4 \%$ \\
\hline & $\stackrel{\overrightarrow{0}}{\stackrel{\partial}{ٍ}}$ & $8.1 \%$ & $16.2 \%$ & $29.7 \%$ & $45.9 \%$ & $100.0 \%$ \\
\hline
\end{tabular}


Table 7: Symmetric Measures for table 6

\begin{tabular}{|l|l|l|l|l|}
\hline & Value & $\begin{array}{l}\text { Asymp. } \\
\text { Std. } \\
\text { Error }^{\mathrm{a}}\end{array}$ & $\begin{array}{l}\text { Approx. } \\
\mathrm{T}^{\mathrm{b}}\end{array}$ & $\begin{array}{l}\text { Approx. } \\
\text { Sig. }^{\mathrm{a}}\end{array}$ \\
\hline $\begin{array}{l}\text { Nominal Contingency } \\
\text { by Coefficient } \\
\text { Nominal }\end{array}$ & .347 & & & .829 \\
$\begin{array}{l}\text { Interval Pearson's R } \\
\text { by } \\
\text { Interval }\end{array}$ & -.015 & .136 & -.090 & $.929^{\mathrm{c}}$ \\
$\begin{array}{l}\text { Ordinal by Ordinal } \\
\text { Spearman Correlation }\end{array}$ & .041 & .158 & .245 & $.808^{\mathrm{c}}$ \\
\hline
\end{tabular}

a. Not assuming the null

hypothesis.

b. Using the asymptotic standard error assuming the null hypothesis.

c. Based on normal approximation.

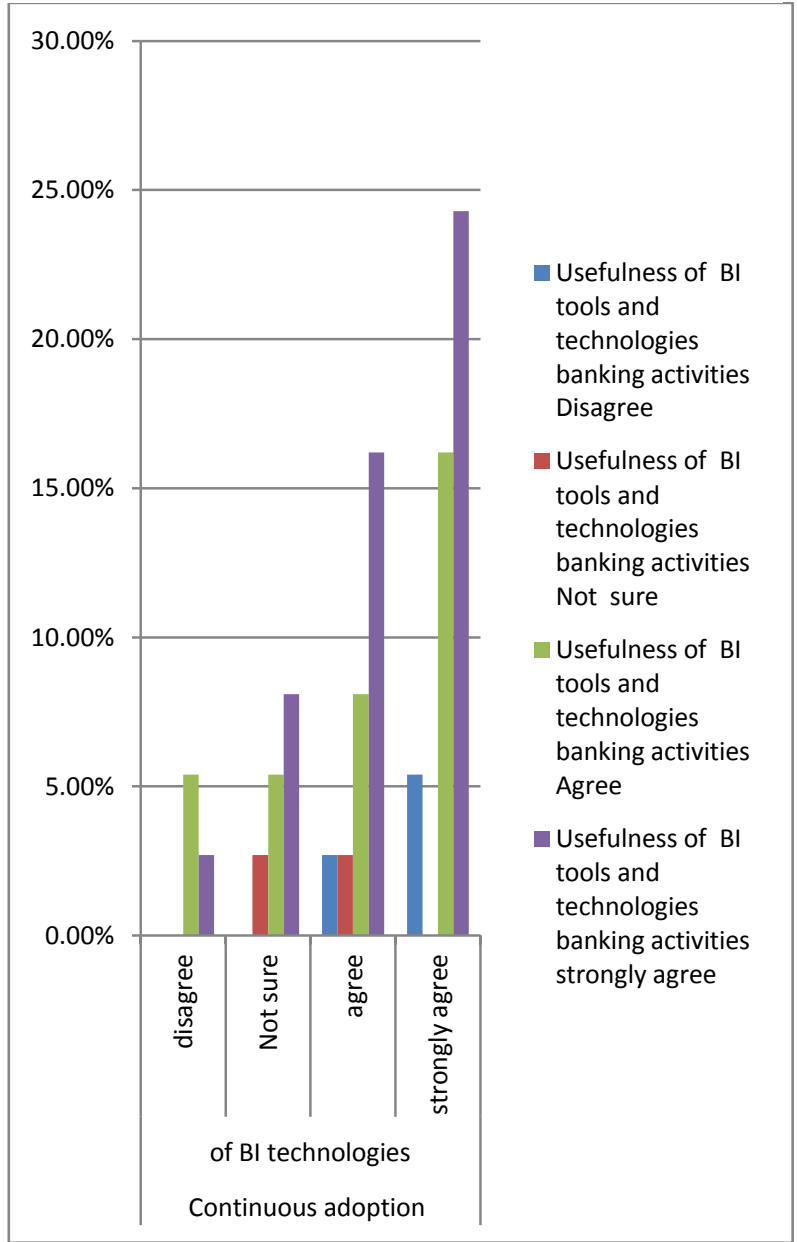

Figure 9: Usefulness of BI tools and technologies banking activities * Continuous adoption of BI technologies.

\section{CONCLUSIONS}

Our research has shown a great significance growth of interest and continuous engagement of business intelligence tools in the banking sector for effective decision making. Even though the tools and approaches engaged are evolving over time, the continuous development training programs offered by banks to their information staff in that sector and the overwhelming engagement of graduate students in the sector is increasing. The gap of gender balancing in the sector is highly needed to bridge the gap between technology divide male and female.

\section{REFERENCES}

[1] Hannula M., Perrtimaki, V., 2003. "Business Intelligence empirical study on top 50 Finnish Companies". Journal of American Academy of Business, Cambridge.

[2] Bach, M. Pejic, Nikola Vlahovic, and Blazenka Knezevic. "Public data retrieval with software agents for business intelligence." Proceedings of the 5th WSEAS Int. Conf. on Applied Informatics and. 2005.

[3] Tabatabaei, S. H., 2009. "Evaluation of Business Intelligence Maturity Level in Iranian Banking Industry". Tarbiat Modares University, Tehran- Iran.

[4] Baraghani, S. N. (2007). "Factors influencing the adoption of internet banking". Tarbiat Modares University, Tehran-Iran.

[5] Hill, J. \& Scott, T, (2004). "A consideration of the roles of business intelligence and e-business in management and marketing decision making in knowledge-based and high-tech start-ups". Qualitative market research, Vol. 7, pp. $48-57$.

[6] Herschel, R, T. \& Jones, N, E. "Knowledge management and business intelligence: the importance of integration", Journal of Knowledge Management, Vol. 9, pp. 45-55.

[7] Reinschmidt, J. \& Allison, F, (2000). "Business Intelligence Certification Guide". IBM Redbooks publication.

[8] Chou, D, C. \& Tripuramallu 2005, H, B. "BI and ERP integration". Information Management \& Computer Security, Vol. 13.

[9] Turban, E., Sharda, R., Aronson, J.E., Kina, D. (2008), "Business Intelligence a managerial approach", Pearson Education Inc., New Jersey, p. 225

[10] Azvine,B, Cui, Z \& Nauck,D, (2005). "Towards realtime business intelligence”, BT Technology Journal, Vol. 23, 2005, pp. 214-25.

[11] Michalewicz, Z., Schmidt, M., Michalewicz, M. \& Chiriac, C. "Adaptive Business Intelligence". SpringerVerlag, Berlin Heidelberg, 2007.

[12] Abu-Dalbouh, H.M. (2013). "A questionnaire approach based on the technology acceptance model for mobile tracking on patient progress applications". Journal of Computer Science. ISSN: 1549-3636. 2013

[13] Venkatesh, V., Morris, M.G., Davis, F.D., and Davis, G.B. "User Acceptance of Information Technology: Toward a Unified View," MIS Quarterly, 27, 2003, 425478. 